\title{
Serum amyloid $A$ is elevated in the serum of lung cancer patients with poor prognosis
}

\author{
WCS Cho*,', TT Yip ${ }^{2}$, WW Cheng' and JSK Au' \\ 'Department of Clinical Oncology, Queen Elizabeth Hospital, 30 Gascoigne Road, Kowloon, Hong Kong; ${ }^{2}$ Ciphergen Biosystems Inc, Fremont, CA, USA
}

\begin{abstract}
BACKGROUND: Lung cancer is known as the top cancer killer in most developed countries. However, there is currently no promising diagnostic or prognostic biomarker for lung cancer. This study aims to discover non-invasive differential markers in the serum of lung cancer patients, to determine the protein identity of the candidate biomarker(s), and to investigate any clinical implication of the biomarker(s) concerned.

METHODS: Blood specimens were collected from 154 pre-operative patients with lung cancer and 35 healthy blood donors with no evidence of lung cancer. Fractionated serum samples were processed by surface-enhanced laser desorption/ionisation time-of-flight mass spectrometry (MS). Candidate biomarker was identified using sodium dodecyl sulphate polyacrylamide gel electrophoresis and tryptic digestion followed by tandem MS fragmentation analysis, which was subsequently validated with immunoassay.

RESULTS: A differential protein with $\mathrm{m} / \mathrm{z}$ | $1.6 \mathrm{kDa}$ was detected and identified as an isoform of human serum amyloid $\mathrm{A}$ (SAA). It was significantly increased by $1822 \%$ in lung cancer patients when compared with the healthy controls, which gave an area under the receiver operator characteristic curve of 0.88 . In addition, the protein was also significantly elevated by $77 \%$ in lung cancer patients with survival $<5$ years when compared with patients with survival $\geqslant 5$ years.

CONCLUSION: There are several functions of the SAA protein, described in the context of inflammation, that are compatible with the mechanism of tumour invasion and metastasis. Our study not only detected increased SAA level in the serum of lung cancer patients but also identified that elevated SAA level may be a non-invasive biomarker useful for the prediction of lung cancer prognosis.

British Journal of Cancer (20 I0) 102, I731-1735. doi: 10.1038/sj.bjc.6605700 www.bjcancer.com

Published online 25 May 2010

(c) 2010 Cancer Research UK
\end{abstract}

Keywords: lung cancer, proteinchip; proteomics; SELDI-TOF-MS; serum amyloid A; serum biomarker

Lung cancer is known as the top cancer killer in most developed countries. Despite marked progress in the treatment, most patients still die of the disease within several months to a few years. The majority of lung cancer is diagnosed at a relatively late stage, and recurrence is common even after optimal therapy. However, there is currently no promising diagnostic or prognostic biomarker for this lethal disease (Cho, 2007a, 2010a). Proteins are the workhorse molecules of life. As proteome changes in response to cancer, it is of great interest to medical researchers. There is hope that oncoproteomics research may help to develop new approaches for early cancer diagnosis, to determine the best therapies for individual patients with specific types of cancer, and to predict whether cancer will recur after treatment (Cho and Cheng, 2007; Cho, 2007b; Cohen et al, 2008; Gámez-Pozo et al, 2009; Han et al, 2009). In recent years, proteomics has been propelled by advances in mass spectrometry (MS) that high-throughput protein profiling enables large-scale screening of proteins within a small sample volume (Cho, 2009). This study aims to use protein profiling for the identification of serum biomarkers that can distinguish patients with lung cancer from healthy controls, as well as differentiate lung cancer patients between poor prognosis and good prognosis, which may potentially provide non-invasive

*Correspondence: Dr WCS Cho; E-mail: chocs@ha.org.hk

Received 30 March 20 I0; revised I5 April 20 I0; accepted 26 April 20 10; published online 25 May 2010 biomarkers for the detection of lung cancer and the prediction of survival in lung cancer patients.

\section{MATERIALS AND METHODS}

\section{Serum samples}

Human sera were obtained through hospital-approved protocols at the Queen Elizabeth Hospital in Hong Kong from each non-fasting individual with provision of informed consent indicating voluntary participation. Specimens were collected from pre-operative patients diagnosed with lung cancer $(n=154)$ and blood donors with no evidence of lung cancer $(n=35)$. Information was collected from each patient pertaining to age and gender. Healthy controls were selected from an archive of blood samples on the basis of matching for age, sex, minimum previous handling, and time period of collection similar to the lung cancer group. The average age \pm standard error of the mean (s.e.m.) for the lung cancer patients was $65.5 \pm 0.9$ years. Among these patients, $83.8 \%$ were male $(n=129)$ and $16.2 \%$ were female $(n=25)$. Regarding the stages of the disease, 55\% $(n=85)$ of the patients were diagnosed with early-stage lung cancer and $45 \%(n=69)$ were diagnosed with advanced-stage lung cancer. Within the cancer samples, $34.4 \%$ were squamous-cell carcinoma samples $(n=53)$, $32.5 \%$ adenocarcinoma $(n=50), 8.4 \%$ other non-small-cell lung cancer $(n=13)$, and $24.7 \%$ small-cell lung cancer $(n=38)$. 
A volume of $5 \mathrm{ml}$ of blood sample from each participant was allowed to clot for $30 \mathrm{~min}$ to $1 \mathrm{~h}$ at room temperature and was centrifuged at $1500 \mathrm{~g}$ for $10 \mathrm{~min}$. All sera were aliquoted and frozen at $-70^{\circ} \mathrm{C}$ until thawed specifically for protein profiling.

\section{Sample fractionation}

To increase the detection of a larger number of peaks, as well as to alleviate signal suppression effects on low-abundant proteins from high-abundant proteins such as albumin, serum samples were fractionated into six fractions containing proteins separated roughly on the basis of their isoelectric points, as previously described (Cho et al, 2007). Briefly, $20 \mu \mathrm{l}$ of each serum sample was diluted during fractionation in $30 \mu \mathrm{l}$ of $50 \mathrm{~mm}$ Tris-HCl buffer ( $\mathrm{pH}$ 9) containing $9 \mathrm{M}$ urea and 2\% 3-((3-cholamidopropyl) dimethylammonio)-1-propanesulfonate (CHAPS). A further dilution was made in $50 \mathrm{~mm}$ Tris- $\mathrm{HCl}$ buffer $(\mathrm{pH}$ 9) containing $1 \mathrm{M}$ urea and $0.22 \%$ CHAPS. Serum samples were loaded onto each well of a 96-well filter plate pre-filled with a Q Hyper DF anionic exchange sorbent (Ciphergen Biosystems, Fremont, CA, USA) and eluted in a stepwise $\mathrm{pH}$ gradient using a Biomek 2000 liquid-handling robot (Beckman Coulter, Fullerton, CA, USA), as described by the manufacturer. The fractions contained the flow-through proteins eluted with $\mathrm{pH} 7,5,4$, and 3, and an organic buffer. Each of the six fractions was collected twice and the two collections were pooled. This helped to ensure the $\mathrm{pH}$ changes appropriately and also gave greater reproducibility in the fractionation, as well as better partitioning of proteins into their respective fractions.

\section{Protein profiling}

Fractioned serum samples were processed for surface-enhanced laser desorption/ionisation time-of-flight (SELDI-TOF) MS (Ciphergen Biosystems) analysis using the eight-spot weak cation exchange (WCX2) ProteinChip (Ciphergen Biosystems) as previously described (Au et al, 2008). Each sample was assayed in duplicate, having duplicate samples randomly placed on different proteinchips with the aid of a 96-well bioprocessor. A pooled quality control sample prepared in the same manner was applied to duplicate spots on each proteinchip used in the experiment as a reproducibility control. To equilibrate the proteinchips, $150 \mu \mathrm{l}$ of binding buffer $(100 \mathrm{mM}$ sodium acetate at $\mathrm{pH} 4)$ was added into each well. The bioprocessor was sealed and incubated with the samples at room temperature for $5 \mathrm{~min}$, with vigorous agitation on a MicroMix 5 shaker (Diagnostics Products Corporation, NJ, USA). The buffer was removed after vortexing. To bind samples onto the proteinchips, $90 \mu \mathrm{l}$ of binding buffer $(100 \mathrm{mM}$ sodium acetate at $\mathrm{pH} 4)$ and $10 \mu \mathrm{l}$ of fractioned sample was added into each well and vortexed for $30 \mathrm{~min}$ at room temperature. A further $150 \mu \mathrm{l}$ of binding buffer $(100 \mathrm{mM}$ sodium acetate at $\mathrm{pH} 4)$ was added into each well and vortexed for $5 \mathrm{~min}$ at room temperature. The excess sera mixtures were discarded after vortexing. The proteinchips were washed twice with de-ionised water and then removed from the bioprocessor. A saturated solution of $1 \mu \mathrm{l}$ sinapinic acid (Ciphergen Biosystems) in 50\% (v/v) acetonitrile and 0.5\% (v/v) trifluoroacetic acid was applied twice to each spot and air dried for $10 \mathrm{~min}$ between the applications. The proteinchips were air-dried and analysed using a proteinchip reader PBS-IIc (Ciphergen Biosystems) with acquisition up to $200 \mathrm{kDa}$. Spectra were collected by the accumulation of 232 shots at laser intensity 180 in a positive mode. The protein masses were calibrated externally using the all-in-one peptide standard (Ciphergen Biosystems).

\section{Protein identification}

The differential protein of interest between the cancer sera and healthy controls was identified with sodium dodecyl sulphate polyacrylamide gel electrophoresis (SDS-PAGE) and tryptic digestion followed by tandem MS fragmentation analysis. Proteins fractionated at organic solvent eluant from the anion exchange filters were characterised by SDS-PAGE. The protein band containing the desired biomarker was cut from the gel and subjected to overnight tryptic digestion. Protein identification was confirmed by tandem MS fragmentation analysis of the peptide generated from the tryptic digest. Tandem MS fragmentation of the peptide generated a set of tandem MS ion fingerprint data, which was exported for database matching and subsequent identification using the Mascot program (Matrix Science Inc, Boston, MA, USA).

Quantitative analysis of serum samples for serum amyloid $A$ The concentration of serum amyloid A (SAA) was determined in both the lung cancer sera $(n=38)$ and the healthy control sera $(n=34)$ using a commercially available immunoassay kit (BioSource, Brussels, Belgium), and the analysis was performed according to the manufacturer's instructions.

\section{Statistical analysis}

The CiphergenExpress software version 3.0.6 (Ciphergen Biosystems) was used to compare serum protein profiles to discover peaks that were differentially expressed between two comparable groups. To visualise the protein peaks that differed in the majority of samples in one group compared with the majority of samples in the other, principal components analysis (PCA) was performed to reduce the dimensionality of the data set and to identify new meaningful underlying variables with visualisation by three-dimensional PCA display. Hierarchical clustering was also conducted and visualised by heat map, a graphical representation of the entire array in grid form with columns representing samples and rows showing the mass-to-charge ratio $(\mathrm{m} / \mathrm{z})$ of protein peaks. For univariate analysis, the average normalised intensity of each peak was calculated for the comparable groups. The difference in group means was reported as the percentage of change, that is, the percentage of (average intensity of one group - average intensity of the compared group)/average intensity of the compared group. The comparison of $P$-values was analysed by the non-parametric Mann - Whitney $U$-test; a peak was deemed to show a statistically significant difference in group means if its $P$-value was $<0.05$. In addition, the receiver operator characteristic analysis of each protein peak was performed for the comparable groups, with the area under the curve value calculated for each peak.

\section{RESULTS}

\section{Serum protein profiling in lung cancer patients}

A total of 245 peaks were detected with $\mathrm{m} / \mathrm{z}$ ranging from 1 to $197 \mathrm{kDa}$. Of these, 53 peaks were generated from fraction 1 ( $\mathrm{pH} 9$ and flow through), 43 peaks were generated from fraction 2 ( $\mathrm{pH} 7)$, 28 peaks were generated from fraction $3(\mathrm{pH} \mathrm{5)}, 38$ peaks were generated from fraction $4(\mathrm{pH} 4), 39$ peaks were generated from fraction $5(\mathrm{pH} 3)$, and 44 peaks were generated from fraction 6 (organic eluant).

\section{Detection of lung cancer}

Comparison of the protein profiles using three-dimensional PCA (Figure 1A) and hierarchical clustering analysis (Figure 1B) showed that the serum profiles of patients with lung cancer $(n=154)$ could be separated from the healthy control group $(n=35)$. There were 140 peaks with significant discriminatory value at distinguishing the lung cancer sera from the healthy control sera. The 10 most discriminating peaks were shown in Table 1A. 

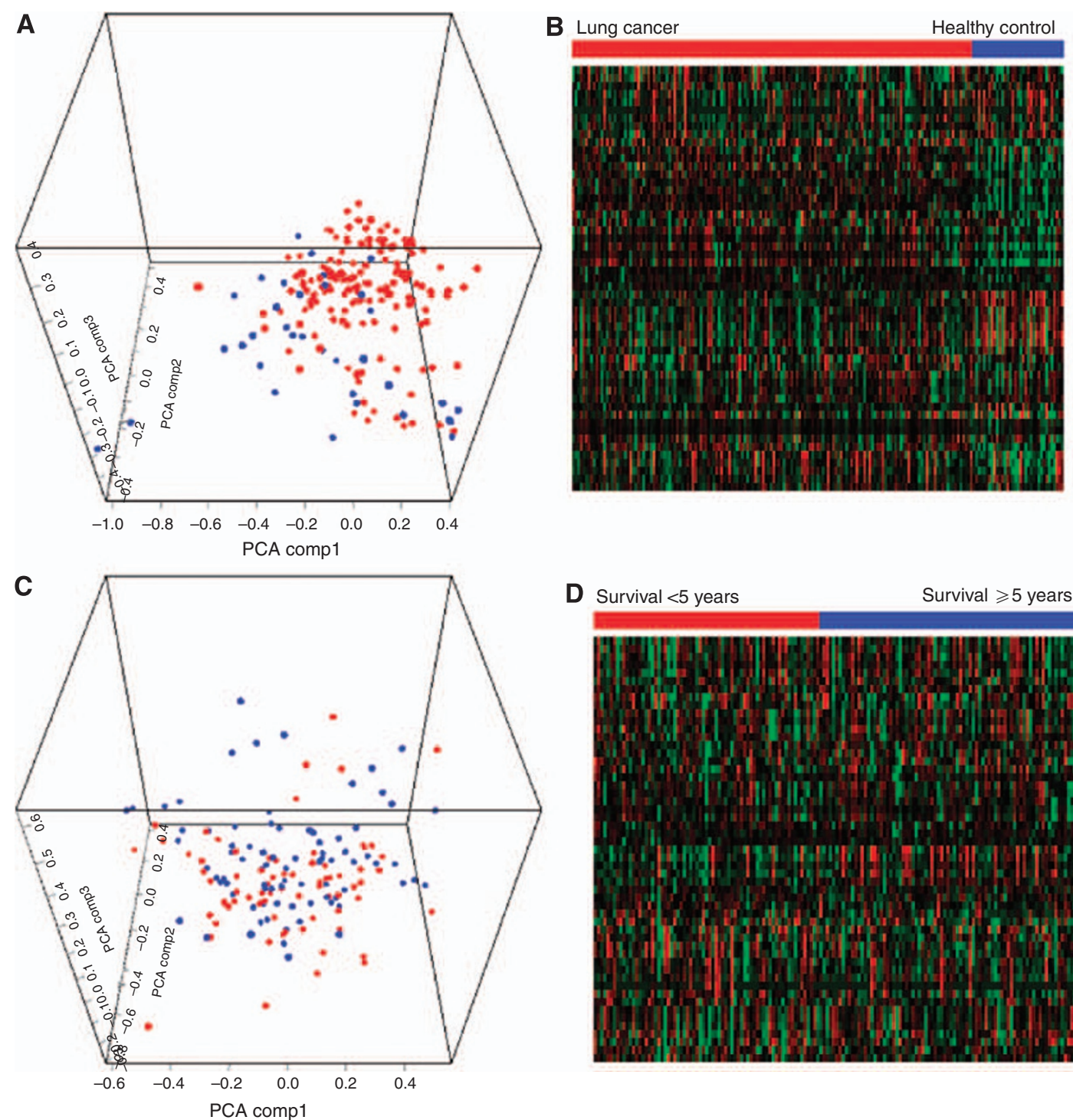

\section{S}

Survival $<5$ years $\quad$ Survival $\geqslant 5$ years

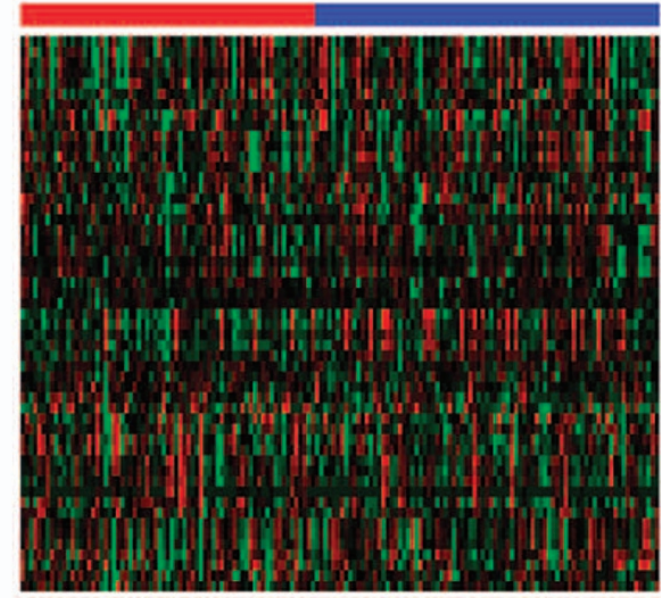

Figure I Multivariate analysis: three-dimensional principal components analysis (PCA) and hierarchical clustering analysis (red, upregulated; green, downregulated). (A) PCA for healthy control $(n=35)$ vs lung cancer $(n=154)$. (B) Hierarchical clustering analysis for healthy control ( $n=35)$ vs lung cancer $(n=154)$. (C) PCA for patients with survival $\geqslant 5$ years $(n=83)$ vs patients with survival $<5$ years $(n=7 \mathrm{I})$. (D) Hierarchical clustering analysis for patients with survival $\geqslant 5$ years $(n=83)$ vs patients with survival $<5$ years $(n=71)$.

\section{Predicting survival}

To discriminate the good prognosis group (survival $\geqslant 5$ years; $n=83$ ) from the poor prognosis group (survival $<5$ years; $n=71$ ), the three-dimensional PCA (Figure 1C) and hierarchical clustering analysis (Figure 1D) were performed. There were 24 peaks with significant discriminatory value at distinguishing the good prognosis group from the poor prognosis group. The 10 most discriminating peaks were shown in Table 1B.

\section{SAA was identified as differential protein}

The overexpression of a protein peak at $11.6 \mathrm{kDa}$ was identified as being significantly differentially expressed in both the diagnosis and prognosis analysis. Two bar charts showed the average normalised intensity of this peak's overexpression in the lung cancer sera $(n=154)$ when compared with the healthy control sera $(n=35)$ (Figure 2A), and the overexpression in the poor prognosis sera $(n=71)$ when compared with the good prognosis sera $(n=83)$ (Figure 2B). The average normalised intensity value was 19.2 -fold higher $(P=1.75 \mathrm{E}-13)$ in the lung cancer sera compared with that in the healthy control sera, and the average expression of the sera from the poor prognosis group was 1.8 -fold higher $(P=3.27 \mathrm{E}-03)$ than the sera from the good prognosis group. Using SDS-PAGE and tryptic digestion followed by tandem MS fragmentation analysis, the differential protein at $11.6 \mathrm{kDa}$ was identified as an isoform of human SAA.

\section{SAA validation by immunoassay}

To validate the peak intensity on the SELDI-TOF-MS protein profile with absolute concentrations determined by routine method, the SAA concentration was measured by an immunoassay kit in samples of both the lung cancer sera $(n=38)$ and the healthy control sera $(n=34)$. The average SAA level was 41.7 -fold higher $(P=1.15 \mathrm{E}-06)$ in the lung cancer sera compared with that in the healthy control sera (Figure 3). 
Table I The top 10 peaks best associated with diagnosis and prognosis ranked by $P$-value

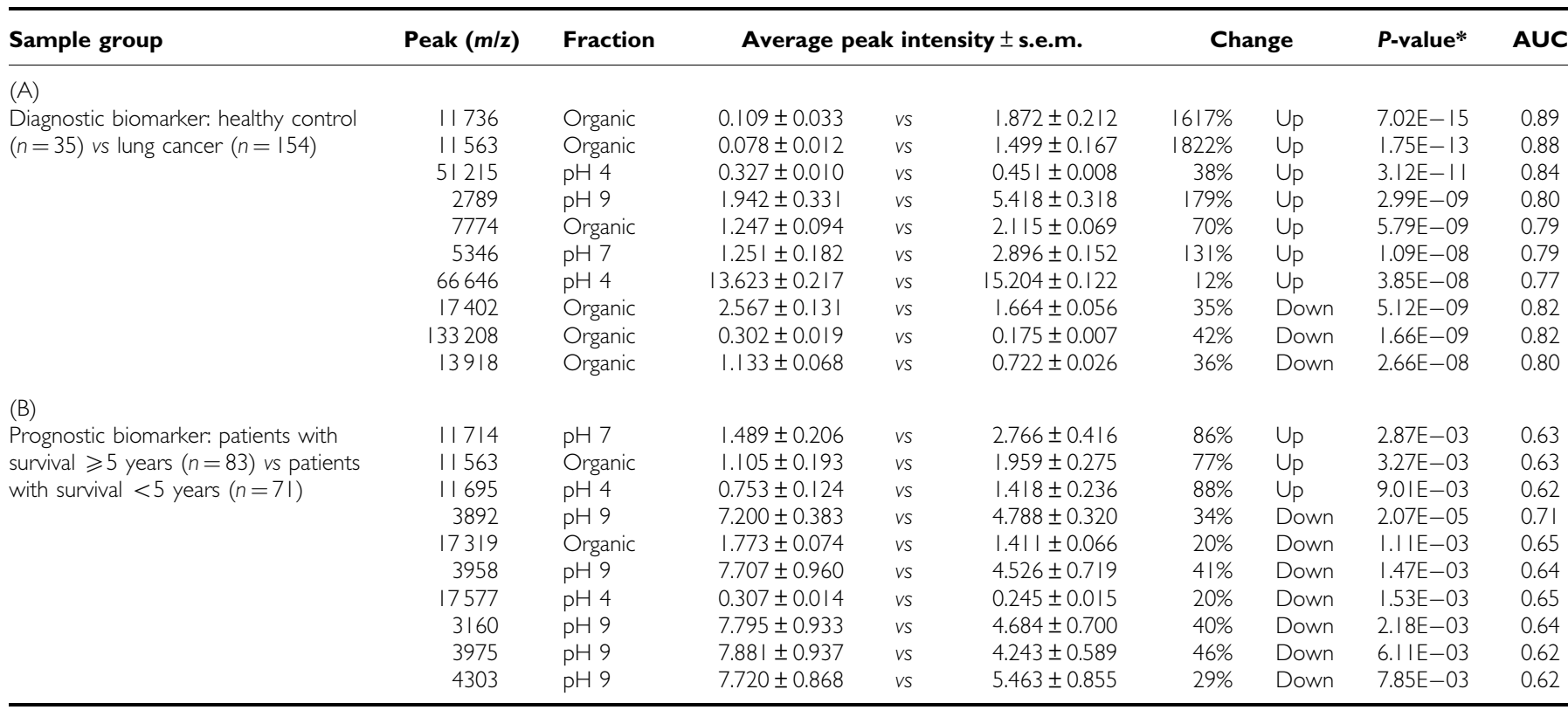

Abbreviations: $A \cup C=$ area under the curve; $\mathrm{m} / \mathrm{z}=$ mass/charge ratio; s.e.m. = standard error of the mean. $* P$-value from Mann-Whitney $U$-test between the comparable groups.
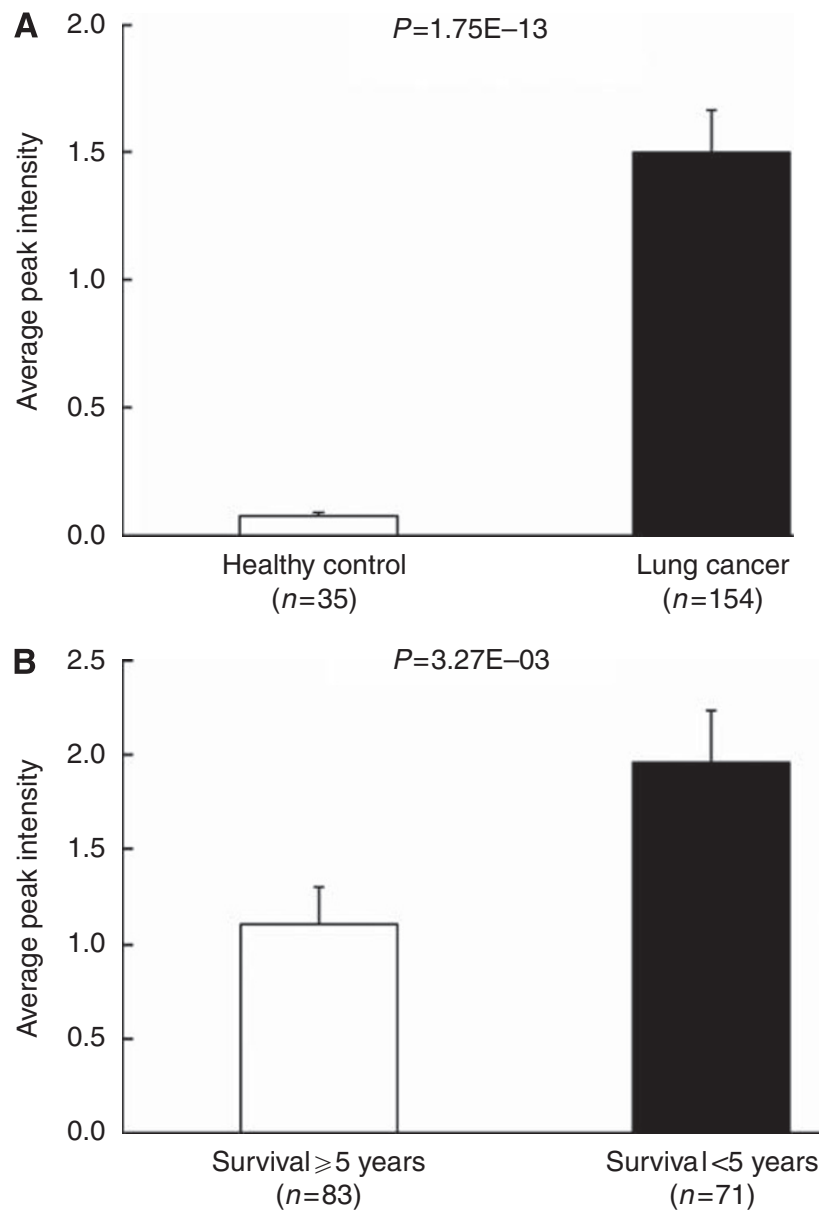

Figure 2 Univariate analysis. (A) Bar chart of potential diagnostic biomarkers at $\mathrm{m} / \mathrm{z} \mid 1.6 \mathrm{kDa}$ for healthy control $(n=35)$ vs lung cancer $(n=154)$. (B) Bar chart of potential prognostic biomarkers at $\mathrm{m} / \mathrm{z} \mid \mathrm{I} .6 \mathrm{kDa}$ for patients with survival $\geqslant 5$ years $(n=83)$ vs patients with survival $<5$ years $(n=7 I)$.

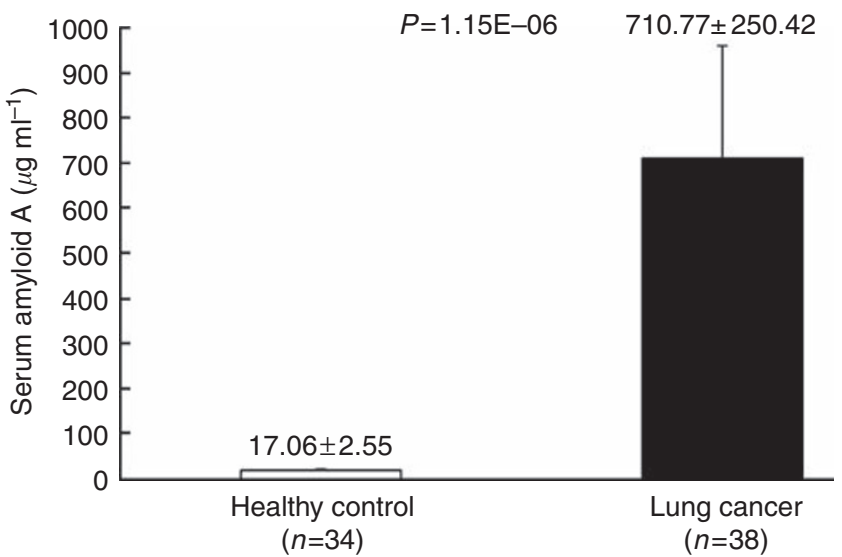

Figure 3 Quantitative analysis of serum samples for serum amyloid $A$. Bar chart of validation by immunoassay on serum amyloid $A$ levels for healthy control $(n=34)$ vs lung cancer $(n=38)$.

\section{DISCUSSSION}

In the omics era, the development of high-throughput technologies that permit the solution of deciphering cancer from higher dimensionality provides a knowledge base that changes the face of cancer understanding and therapeutics (Cho, 2010b). Serum is one of the most easily procured patient specimens and it is perceived to contain many of the molecules that might indicate systemic function. Thus, serum is the sample source that is most often profiled in the hopes of identifying sets of biomarkers for clinical use (Gilbert et al, 2004).

In this study, proteomic analyses of serum samples from patients with lung cancer and controls have identified SAA as an elevated biomarker in lung cancer (as shown by SELDI analysis and confirmed by immunoassay). It is known that SAA is secreted during the acute phase of inflammation; the conservation of this protein throughout invertebrates and vertebrates suggests that SAA has an essential role in all animals including humans (Manley et al, 2006). There are several functions of SAA protein, described 
in the context of inflammation, that are compatible with the mechanism of tumour invasion and metastasis. These properties place SAA as an extracellular matrix-associated adhesion protein with a potential role in tumour pathogenesis. The SAA mRNA expression in epithelial cells was gradually increased as they progressed through different stages of dysplasia to overt carcinoma (Gutfeld et al, 2006). Accumulating evidence has suggested that SAA might be used to detect a pattern of physiological events that reflect the growth of malignancy and host response. Elevated SAA may be a primary product of tumour lesions, but can also be the product of hepatocytes. Further investigation to determine whether cancer tissue-derived cytokines stimulate SAA synthesis in liver or epithelial cells will be interesting (Malle et al, 2009).

Overexpression of SAA has been reported in nasopharyngeal, renal, gastric, hepatocellular, melanoma, breast, and endometrial cancers (Cho et al, 2004; Tolson et al, 2004; Chan et al, 2007; He et al, 2008; Findeisen et al, 2009; Pierce et al, 2009; Ramankulov et al, 2008; Cocco et al, 2009, 2010; Sasazuki et al, 2010; Vermaat et al, 2010). Our study not only detected increased SAA level in the serum of lung cancer patients but also identified that elevated SAA level may be a non-invasive biomarker, useful for the prediction of lung cancer prognosis. As far as we know, the association of SAA with the survival of lung cancer patients has never been reported. Moreover, a number of SELDI peaks were found to be significantly differentiated between the serum of cancer patients and controls, as well as between the poor prognosis patients and good prognosis patients. Further identification of these peaks is awaiting.

Recently, the US Food and Drug Administration has approved an ovarian cancer triage test called OVA1, containing CA125 and four biomarkers ( $\beta_{2}$-microglobulin, transferrin, apolipoprotein $\mathrm{A} 1$, and transthyretin) identified by SELDI-TOF-MS (Fung, 2010). This marks an encouraging step of translating biomarker discovery from laboratory to clinic. It showed that having identified biomarkers by primary screening, a standard assay may then be developed and finally converted into clinically applicable measures. Our results reveal that the level of SAA is highly elevated in lung cancer and in the patients with poor prognosis, thus warranting further studies investigating this candidate biomarker as part of a multimarker test for the diagnosis and prognosis of lung cancer.

\section{REFERENCES}

Au JS, Cho WC, Yip TT, Law SC (2008) Proteomic approach to biomarker discovery in cancer tissue from lung adenocarcinoma among nonsmoking Chinese women in Hong Kong. Cancer Invest 26: 128-135

Chan DC, Chen CJ, Chu HC, Chang WK, Yu JC, Chen YJ, Wen LL, Huang SC, Ku CH, Liu YC, Chen JH (2007) Evaluation of serum amyloid A as a biomarker for gastric cancer. Ann Surg Oncol 14: 84-93

Cho WC (2007a) Potentially useful biomarkers for the diagnosis, treatment and prognosis of lung cancer. Biomed Pharmacother 61: 515-519

Cho WC (2007b) Contribution of oncoproteomics to cancer biomarker discovery. Mol Cancer 6: 25

Cho WC (2009) Proteinchip. In Encyclopedia of Cancer, Schwab M (ed). 2nd edn, Vol. 3, pp 2475-2478. Springer: New York

Cho WC (2010a) Cancer biomarkers (an overview). In Methods of Cancer Diagnosis, Therapy and Prognosis, Hayat MA (ed). Springer: New York, pp 21-40

Cho WC (2010b) Omics approaches in cancer research. In An Omics Perspective on Cancer Research, Cho WC (ed). Springer: New York, pp 1-9.

Cho WC, Cheng CH (2007) Oncoproteomics: current trends and future perspectives. Expert Rev Proteomics 4: 401-410

Cho WC, Yip TT, Ngan RK, Yip TT, Podust VN, Yip C, Yiu HH, Yip V, Cheng WW, Ma VW, Law SC (2007) Proteinchip array profiling for identification of disease- and chemotherapy-associated biomarkers of nasopharyngeal carcinoma. Clin Chem 53: 241-250

Cho WC, Yip TT, Yip C, Yip V, Thulasiraman V, Ngan RK, Yip TT, Lau WH, Au JS, Law SC, Cheng WW, Ma VW, Lim CK (2004) Identification of serum amyloid A protein as a potentially useful biomarker to monitor relapse of nasopharyngeal cancer by serum proteomic profiling. Clin Cancer Res 10: $43-52$

Cocco E, Bellone S, El-Sahwi K, Cargnelutti M, Buza N, Tavassoli FA, Schwartz PE, Rutherford TJ, Pecorelli S, Santin AD (2010) Serum amyloid A: a novel biomarker for endometrial cancer. Cancer 116: 843-851

Cocco E, Bellone S, El-Sahwi K, Cargnelutti M, Casagrande F, Buza N, Tavassoli FA, Siegel ER, Visintin I, Ratner E, Silasi D-A, Azodi M, Schwartz PE, Rutherford TJ, Pecorelli S, Santin AD (2009) Serum amyloid A (SAA): a novel biomarker for uterine serous papillary cancer. Bri J Cancer 101: 335-341

Cohen AA, Geva-Zatorsky N, Eden E, Frenkel-Morgenstern M, Issaeva I, Sigal A, Milo R, Cohen-Saidon C, Liron Y, Kam Z, Cohen L, Danon T, Perzov N, Alon U (2008) Dynamic proteomics of individual cancer cells in response to a drug. Science 322: 1511-1516

Findeisen P, Zapatka M, Peccerella T, Matzk H, Neumaier M, Schadendorf D, Ugurel S (2009) Serum amyloid A as a prognostic marker in melanoma identified by proteomic profiling. J Clin Oncol 27: 2199-2208

Fung ET (2010) A recipe for proteomics diagnostic test development: the OVA1 test, from biomarker discovery to FDA clearance. Clin Chem 56: 327-329

Gámez-Pozo A, Sánchez-Navarro I, Nistal M, Calvo E, Madero R, Díaz E, Camafeita E, de Castro J, López JA, González-Barón M, Espinosa E,
Fresno Vara JA (2009) MALDI profiling of human lung cancer subtypes. PLoS One 4: e7731

Gilbert K, Figueredo S, Meng XY, Yip C, Fung ET (2004) Serum proteinexpression profiling using the proteinchip biomarker system. In Methods in Molecular Biology. Vol 264. Protein Arrays Methods and Protocols Fung ET (ed), pp 259-268. Humana Press Inc: Totowa

Gutfeld O, Prus D, Ackerman Z, Dishon S, Linke RP, Levin M, Urieli-Shoval S (2006) Expression of serum amyloid A, in normal, dysplastic, and neoplastic human colonic mucosa: implication for a role in colonic tumorigenesis. J Histochem Cytochem 54: 63-73

Han MK, Oh YH, Kang J, Kim YP, Seo S, Kim J, Park K, Kim HS (2009) Protein profiling in human sera for identification of potential lung cancer biomarkers using antibody microarray. Proteomics 9: 5544-5552

He QY, Zhu R, Lei T, Ng MY, Luk JM, Sham P, Lau GK, Chiu JF (2008) Toward the proteomic identification of biomarkers for the prediction of HBV related hepatocellular carcinoma. J Cell Biochem 103: 740-752

Malle E, Sodin-Semrl S, Kovacevic A (2009) Serum amyloid A: an acutephase protein involved in tumor pathogenesis. Cell Mol Life Sci 66: 9-26

Manley PN, Ancsin JB, Kisilevsky R (2006) Rapid recycling of cholesterol: the joint biologic role of $\mathrm{C}$-reactive protein and serum amyloid A. Med Hypotheses 66: 784-792

Pierce BL, Ballard-Barbash R, Bernstein L, Baumgartner RN, Neuhouser ML, Wener MH, Baumgartner KB, Gilliland FD, Sorensen BE, Tiernan $\mathrm{AM}$, Ulrich CM (2009) Elevated biomarkers of inflammation are associated with reduced survival among breast cancer patients. J Clin Oncol 27: 3437-3444

Ramankulov A, Lein M, Johannsen M, Schrader M, Miller K, Loening SA, Jung K (2008) Serum amyloid A as indicator of distant metastases but not as early tumor marker in patients with renal cell carcinoma. Cancer Lett 269: 85-92

Sasazuki S, Inoue M, Sawada N, Iwasaki M, Shimazu T, Yamaji T, Shoichiro T for the Japan Public Health Center-Based Prospective Study Group (2010) Plasma levels of C-reactive protein and serum amyloid A and gastric cancer in a nested casecontrol study: Japan Public Health Center-based prospective study. Carcinogenesis 31: 712-718

Tolson J, Bogumil R, Brunst E, Beck H, Elsner R, Humeny A, Kratzin H, Deeg M, Kuczyk M, Mueller GA, Mueller CA, Flad T (2004) Serum protein profiling by SELDI mass spectrometry: detection of multiple variants of serum amyloid alpha in renal cancer patients. Lab Invest 84: $845-856$

Vermaat JS, van der Tweel I, Mehra N, Sleijfer S, Haanen JB, Roodhart JM, Engwegen JY, Korse CM, Langenberg MH, Kruit W, Groenewegen G, Giles RH, Schellens JH, Beijnen JH, Voest EE (2010) Two-protein signature of novel serological markers apolipoprotein-A2 and serum amyloid alpha predicts prognosis in patients with metastatic renal cell cancer and improves the currently used prognostic survival models. Ann Oncol; doi: 10.1093/annonc/mdp559 